\title{
The Fallopian tubes in domestic mammals: how vital is their physiological activity?
}

\author{
Ronald Henry Fraser HUNTER* \\ Department of Clinical Studies - Reproduction, Royal Veterinary and Agricultural University, \\ 1870 Frederiksberg C, Copenhagen, Denmark
}

\begin{abstract}
Set in an historical perspective, this essay examines diverse physiological aspects of Fallopian tube function in domestic animals and man. Microsurgical experiments are described that established the role of the isthmus in imposing a sperm gradient up to the site of fertilisation. Resection of the isthmus followed by reanastomosis of the remaining portions of the tube generated a high incidence of polyspermy in mated animals. Scanning electron microscopy and surgical studies revealed that spermatozoa were arrested and stored in the caudal portion of the isthmus before ovulation, the so-called functional sperm reservoir. There were specific adhesion contacts between the sperm head and endosalpingeal microvilli or cilia. Further experiments indicated that very large numbers of competent spermatozoa could be released from pre-ovulatory binding by microinjections of a solution of progesterone in oil under the serosal layer of the tube: when suitably timed, such treatment led to a high incidence of polyspermic fertilisation. Avid sperm binding in the caudal isthmus before ovulation prevents myosalpingeal activity leading to abnormal fertilisation, as might occur with multiple mating. Temperatures in the reproductive system were assessed and the caudal isthmus was found to be cooler than the ampulla during the pre-ovulatory phase of sperm storage. Finally, the existence of fluid microenvironments within the Fallopian tubes was reported, and the role of suspended cumulus-corona cells in amplifying signals from the zygote examined. An impact of Fallopian tube fluids on embryonic gene expression was also considered - an influence that may be further imposed if such fluids have access to the uterine lumen.
\end{abstract}

tubal anastomosis / isthmus / sperm gradient / fertilisation / polyspermy / microenvironments / temperature

\section{INTRODUCTION}

It is a pleasure to be here in Paris among many of my former colleagues from Jouyen-Josas in those far-off and happy days of 1968-1970. The Department of Animal Physiology at INRA under Professor Charles Thibault was a powerful magnet for postdoctoral fellows. It pulsated with exciting experiments and intellectual rigour, con- tained many young scientists soon to gain an international reputation and lead their own research groups, and offered excellent modern facilities, for example both for surgical and in vitro studies. It was indeed a mecca and one cannot overlook the fact that its life blood some six days a week (yes, one happily worked for much of Saturday) was the dynamic and personable Charles Thibault. In very many ways, it is not easy to accept

* Corresponding author: Ladfield, Oxnam, Jedburgh, TD8 6RJ, Scotland 


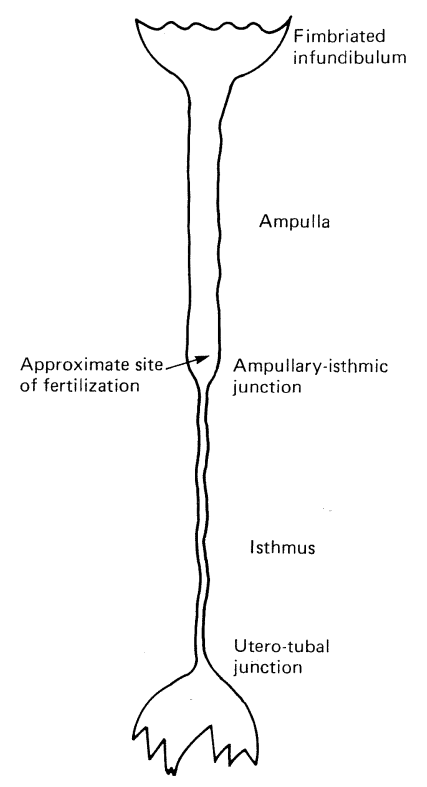

Figure 1. Linear representation of a Fallopian tube to depict the thin-walled ampulla leading into the strongly muscular isthmus. The site of fertilisation - that is of successful gamete fusion - is the region where the ampulla merges into the isthmus.

that he is no longer with us. The loss of this source of wisdom and perspective will be keenly felt, for Charles Thibault was a major intellectual force, witnessed not least by his Presidency of CNRS under Giscard d'Estaing and as a recipient of prestigious international awards.

This review will cover some of the physiological activities of the Fallopian tubes, a field of considerable interest to Monsieur Thibault who himself prepared a topical review for a conference in Japan [1]. In our own research activities at Jouy-en-Josas and in Edinburgh, Montréal and Copenhagen, my colleagues and I have undertaken diverse studies on Fallopian tube function in domestic animals, in part in small laboratory animals but principally in cows, sheep and pigs. Although useful observations on tubal activity were made in guinea-pigs, golden hamsters and rabbits, this essay will concentrate on work in mature pigs (Fig. 1).
During my time at Jouy-en-Josas, the Institute's surgeon was the medicallytrained Pierre-Claude Léglise, a man of many talents and complex personality, at least as much at home in the company of Jean-Paul Sartre and Simone de Beauvoir as with his scientific colleagues. He had been recruited by Charles Thibault during the build up of the Animal Physiology department in the 1950's and had performed hallmark hypophysectomy studies for Du Mesnil du Buisson. In the operating theatre, he was highly disciplined, completely focused and absolutely meticulous. One of the topics that much interested Léglise in the late 1960's was that of vascular anastomosis, and he was frequently to be found perusing the American Journal of Surgery for the latest developments in this field. At the time of my own arrival at Jouy-en-Josas in September 1968, the regulatory roles performed by the isthmus of the Fallopian tubes were much on my mind, not least in supposedly imposing a gradient in sperm numbers and thereby regulating the normality of fertilisation.

\section{FALLOPIAN TUBE MICROSURGERY}

One of my proposals was to examine the influence of surgical resection of the isthmus and, accordingly, Léglise was approached to see if he would attempt the delicate reanastomosis of the remaining portions of the Fallopian tube. Happily, the requirements were sufficiently close to vascular surgery to fascinate him, and we duly embarked on a large series of microsurgeries in both pigs and rabbits (Fig. 2). As an aside, it is worth noting that Léglise was primarily interested in skilful surgery, not in the underlying scientific questions. Indeed, in our first two specimens examined at autopsy, he was on the verge of discarding the Fallopian tubes after inspecting the successful reanastomosis! He appeared not to appreciate the requirement of perfusing the tubes in order to recover the zygotes and establish the normality of fertilisation after routine mating. 

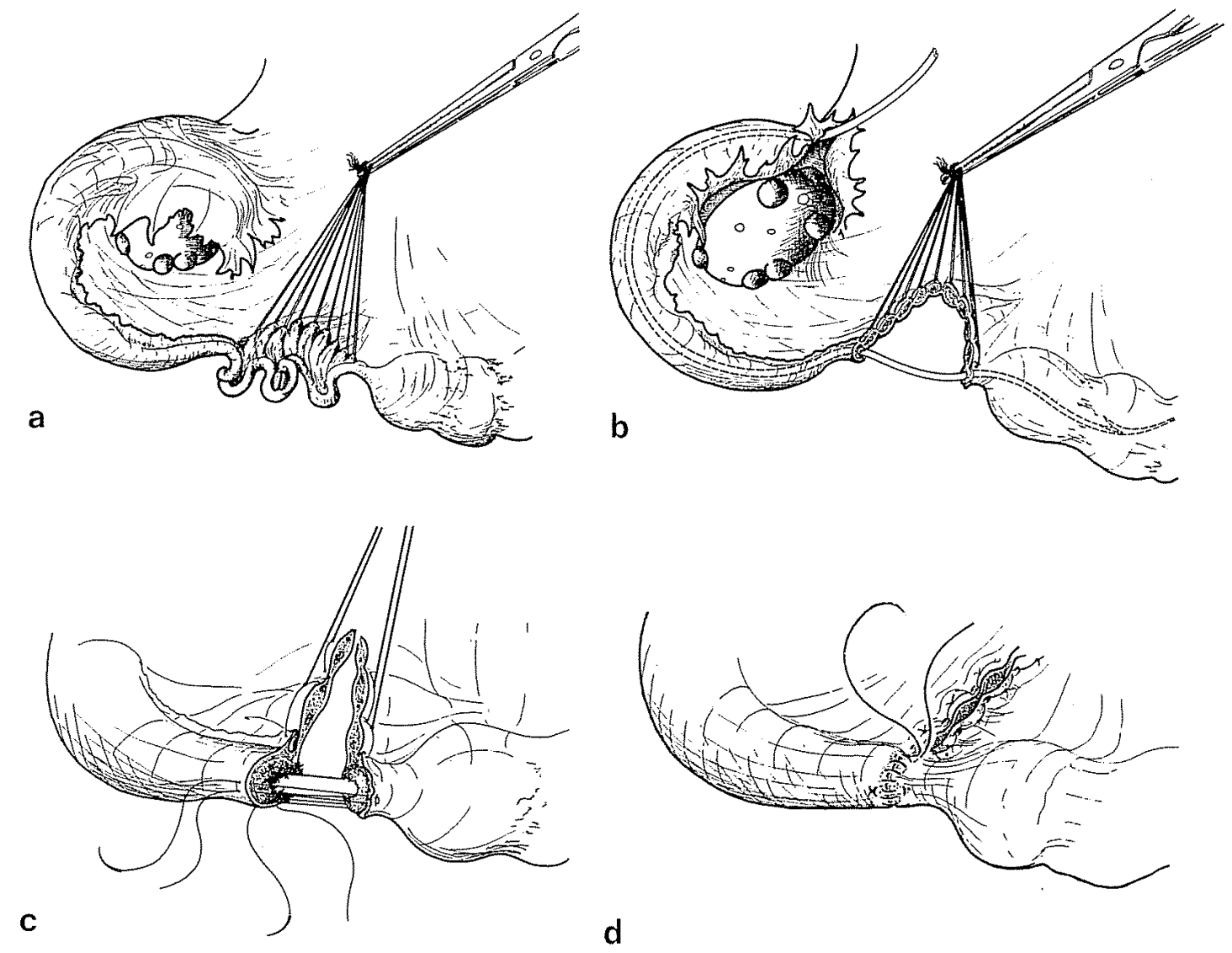

Figure 2. Tubal reconstructive surgery in the domestic pig to examine the influence upon the normality of fertilisation of resecting most of the isthmus followed by end-to-end anastomosis (modified from Hunter and Léglise [2]). 


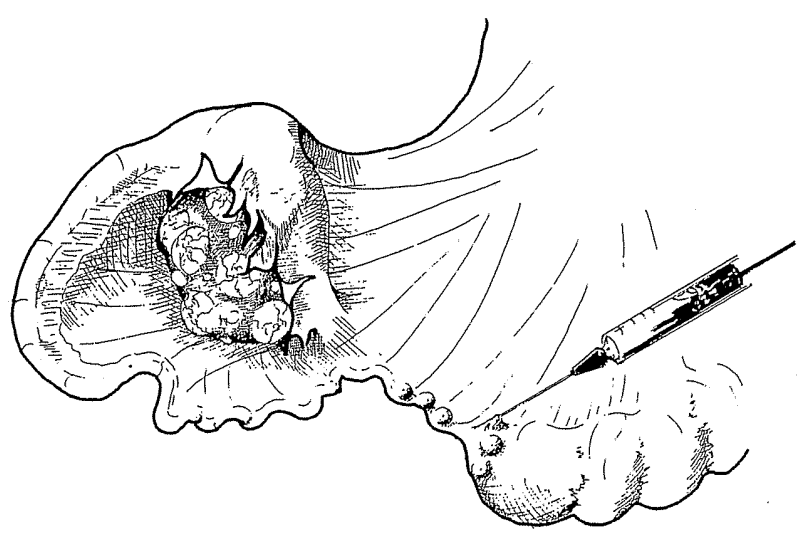

Figure 3. Semi-diagrammatic illustration of one Fallopian tube, proximal uterine horn and portion of a pig ovary bearing pre-ovulatory follicles. Microdroplets of a solution of progesterone in oil injected beneath the serosal layer surrounding the distal isthmus and utero-tubal junction resulted in a $33 \%$ incidence of polyspermy in the eggs subsequently recovered from this tube [36].

He was amused to learn that such a surgical study might have further significance.

In fact, resection of the isthmus followed by reanastomosis of the remaining portions of the tube generated a high incidence of polyspermic fertilisation in both pigs and rabbits, thereby emphasising the critical regulatory role of this portion of the genital duct in terms of sperm numbers [2,3]. As well known to Professor Thibault, polyspermic fertilisation is a pathological condition in mammals, invariably precipitating early death of an embryo [4].

\section{FUNCTIONAL SPERM RESERVOIR}

Following on from this demonstration that the Fallopian tube isthmus regulated sperm ascent to the site of fertilisation, and that therefore there might be an accumulation of viable spermatozoa in the caudal portion of the isthmus, we were able to demonstrate that spermatozoa were indeed sequestered in the caudal isthmus before ovulation and that sperm motility was suppressed in this region. Du Mesnil du Buisson and Dauzier [5] had suspected that either the utero-tubal junction or the isthmus might act as a sperm reservoir, and by surgical and histological studies the latter was shown to be true in pigs [6], sheep [7] and cows [8, 9]. We termed the caudal portion of the isthmus the functional sperm reservoir [10], for it was from this region of the tract that spermatozoa involved in the events of fertilisation were activated and released close to the time of ovulation.

Scanning electron microscopic studies undertaken jointly with $\mathrm{M}$. and Mme Fléchon further emphasised the pre-ovulatory storage of viable spermatozoa in the caudal isthmus and the intimate arrangement of the head with the duct epithelium [11-13]. This orientation of the head had been noted during prolonged sperm storage in bats [14], and soon was to become termed sperm binding on account of the adhesive reaction.

On the basis of earlier studies demonstrating that: (1) sperm binding and release could be influenced in a major way by local treatment of the isthmus wall with microdroplets of progesterone in oil (Fig. 3); (2) progesterone secreted by Graafian follicles is transferred locally by a vascular counter-current system to the wall of the Fallopian tube isthmus in high titres shortly 


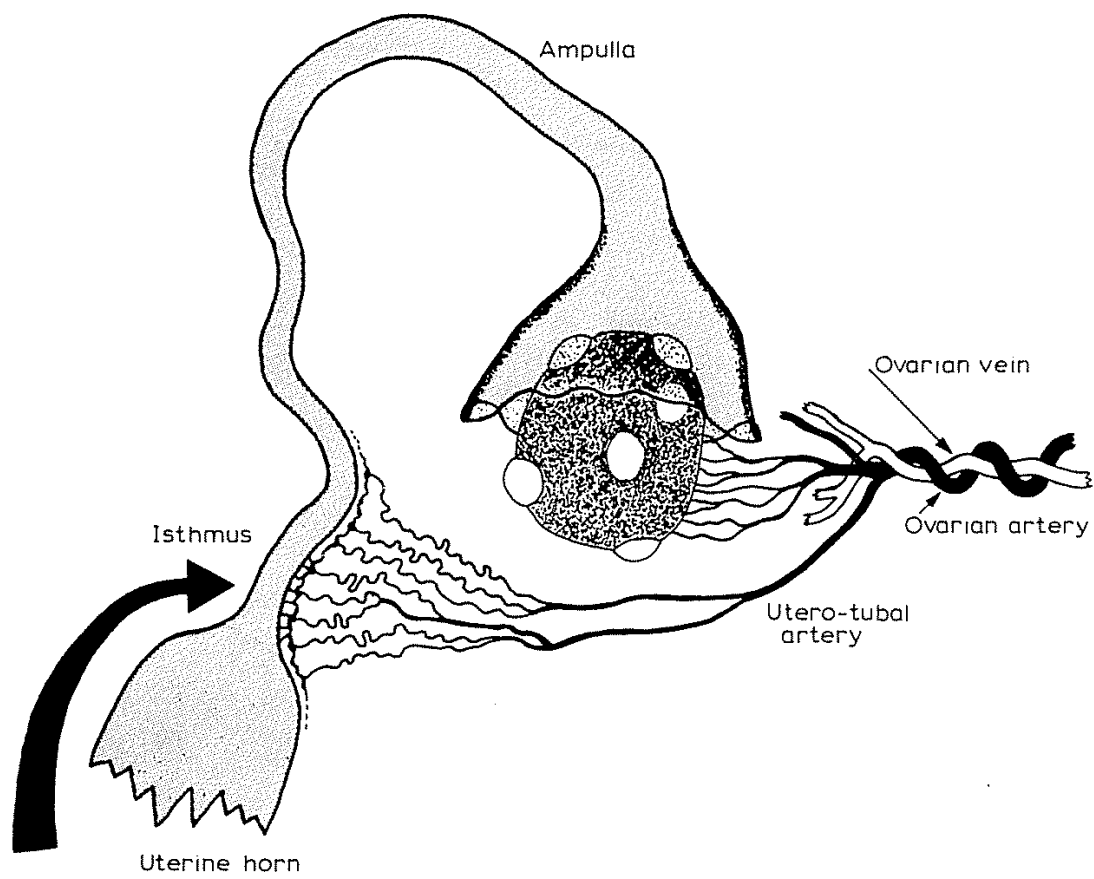

Figure 4. A semi-diagrammatic representation of the arterial blood supply to the ovary and isthmus of the pig Fallopian tube. A portion of the ovarian vein is also shown. A counter-current transfer of follicular hormones was demonstrated from the ovarian vein to the corresponding artery and thus into the utero-tubal branch [37].

before ovulation (Fig. 4), a model was proposed to describe the relevant pre- and periovulatory events (Fig. 5). The model embraces the gonad, the duct and a sperm cell.

\section{SIGNIFICANCE OF SPERM BINDING}

Invariably overlooked during discussion of the phenomenon of binding in the functional sperm reservoir is the physical activity of the myosalpinx. The Fallopian tubes themselves do not rest immotile during the period of oestrus but show marked contractile activity, especially as the time of ovulation approaches. This activity is further enhanced by mating or episodes of multiple mating. Accordingly, were it not for the phenomenon of avid sperm binding in the cau- dal isthmus, large numbers of spermatozoa might be displaced to the site of fertilisation rendering the eggs vulnerable to polyspermy. However, in the physiological situation, initial sperm:egg ratios at the site of fertilisation are close to unity, even after multiple mating before the time of ovulation.

\section{TEMPERATURE IN REPRODUCTIVE SYSTEM}

A further study of relevance to pre-ovulatory sperm storage and peri-ovulatory sperm activation concerned relative temperatures within the lumen of the Fallopian tube. By means of fine thermistor probes introduced into the two extremes of the porcine tube, a temperature gradient could be demonstrated in pre-ovulatory animals: in 


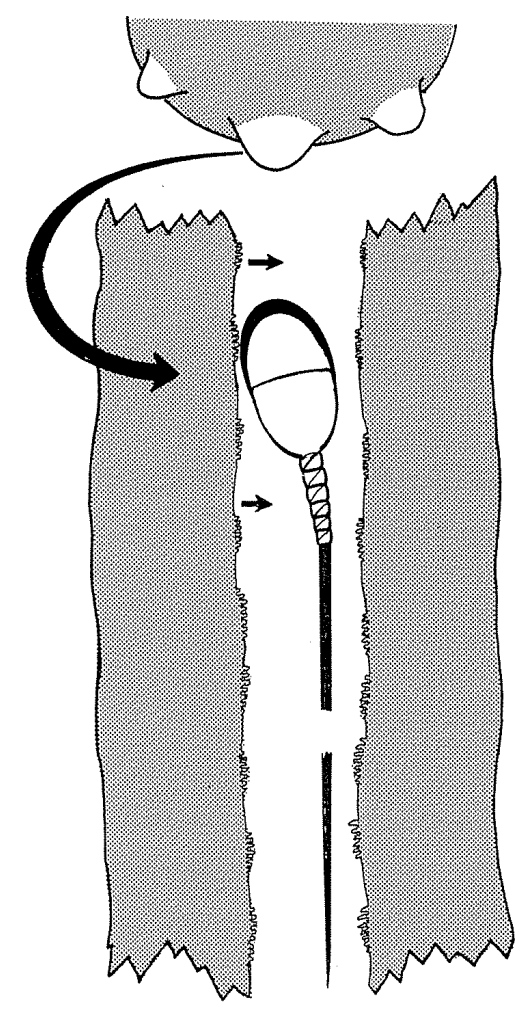

a

Figure 5. Model to illustrate the way in which the endocrine activity of pre- or periovulatory Graafian follicles acts locally via a vascular counter-current system to program the membrane configuration and motility of spermatozoa in the lumen of the Fallopian tube isthmus. Gonadal hormones (from the follicles) act on the tubal epithelium whose transudates and secretions in turn influence the nature of the luminal fluids. Completion of capacitation is reasoned to be a periovulatory event, at least in the large farm species with a protracted interval between the gonadotrophin surge and ovulation. By contrast, a preovulatory strategy in the Fallopian tube would necessarily have been to suppress completion of capacitation. (a) Intact, relatively quiescent spermatozoon under the overall influence of preovulatory follicles. Membrane vesiculation on the anterior part of the sperm head is suppressed, as is the development of whiplash activity in the flagellum, presumably due to local molecular control mechanisms. The lumen of the isthmus is extremely narrow and contains viscous secretions, and myosalpingeal contractions are reduced. The heads of viable spermatozoa are bound to the epithelium. (b) An acrosome-reacted, hyperactive spermatozoon under the influence of Graafian follicles on the point of ovulation. The patency of the isthmus has begun to increase, allowing a more powerful pattern of flagellar beat. Progression of such spermatozoa to the site of fertilisation may also be aided by enhanced contractile activity of the myosalpinx, and yet involves a strict numerical regulation. In fact, hyperactivation and an acrosome reaction in a fertilising spermatozoon may develop only in the vicinity of the egg. A premature acrosome reaction would risk displacement of the vesiculated membranes before the site of fertilisation. The model accords with the observation that high proportions of spermatozoa undergoing the acrosome reaction in ruminants are found predominantly in the ampulla adjoining the ovulatory ovary and only at or following ovulation. 
10 mated animals, the caudal isthmus was a mean of $0.7^{\circ} \mathrm{C}$ cooler than the proximal ampulla, a gradient that was not demonstrable after ovulation [15]. Accordingly, the relatively cooler pre-ovulatory temperature of the caudal isthmus was suggested to contribute to reduced sperm motility and the phase of storage. The objection has been raised that a temperature reduction of $0.7^{\circ} \mathrm{C}$ is too small to influence sperm motility but it needs to be appreciated that these are in vivo, not in vitro, observations and that spermatozoa entering the isthmus from the uterus would have undergone diverse physiological modifications: their membranes, mid-piece and flagellum would be in an especially sensitised condition.

The rôle of temperature and differences in temperature within the female reproductive system appears not to have received detailed study in mammals. However, it is worth noting that pre-ovulatory Graafian follicles, the structures that shed the female gamete at ovulation, show a temperature differential when compared with other tissues in the same ovary, as revealed in rabbits, humans and pigs (reviewed in Hunter [16]). By means of infra-red sensing, preovulatory Graafian follicles in pigs were noted to be a mean of $1.3{ }^{\circ} \mathrm{C}$ cooler than ovarian stroma [17].

Taking these two studies, of genital duct and of gonadal temperatures together, it may be significant that both male and female gametes are exposed to reduced temperature in the hours before the final phase of gamete transport that culminates in spermegg interactions and fertilisation.

\section{FLUID MICROENVIRONMENTS}

Remaining with the question of whether the Fallopian tubes have a vital role in reproductive events, attention could usefully turn to fluids in the lumen. Such fluids vary quantitatively and qualitatively during the oestrous cycle. Furthermore, as detected by electron probe analysis in rodents, there are differences in elemental composition between ampullary and isthmic fluid [18]. Using a surgical approach to regional fluid sampling, a series of differing environments was detected along the duct [19]. Bearing in mind the contractile activity of the myosalpinx, accentuated during the period of oestrus and close to ovulation, a mixing of fluids might have been anticipated, rendering the composition more or less homogeneous. To explain the surprising regional differences, macromolecules in the Fallopian tube such as oviductin have been invoked as a means of stabilising the regional fluid environments [20]. Likewise a role has been attributed to the epithelial microarchitecture of ridges, folds, furrows and grooves in demarcating fluid environments [21].

Moving down from a regional level to a microlevel of fluid composition, there are more recent interpretations that concern the role of gametes, embryos and free-living somatic cells on the fluid environments of the Fallopian tube lumen. Binding of spermatozoa to the isthmus epithelium may alter the nature of protein secretion by the endosalpinx $[22,23]$ whereas the influence of the oocyte may be more subtle and indirect. Ever since the appreciation that large numbers of cumulus-corona cells shed by the recently-ovulated oocyte are not moribund or dead but physiologically active in terms of hormone and peptide synthesis (see Hunter [24]; Motta et al. [25]), a contribution of these cells to the events of fertilisation and on the neighbouring endosalpinx has been considered. Notable points are that the cells remain in suspension in the immediate vicinity of the oocyte or zygote, that they have acted to transmit oocyte signals before liberation and might therefore be in a position to amplify embryonic messages soon after fertilisation. Bearing in mind, too, their close proximity to the endosalpingeal surface, they could influence the micromilieu both in terms of epithelial secretion and transudation [26-28]. 


\section{THE KEY QUESTION}

Despite the above descriptions of their diverse physiological involvements, the question remains as to whether the Fallopian tubes are essential other than in the physical sense of a conduit between the gonad and uterus and perhaps also to enable peritoneal fluid to be in contact with the uterine fluid. Upon the discovery of progesterone and its influence on endometrial proliferation, George Corner considered a principal role of the Fallopian tubes might be to delay passage of embryos until the uterus was suitably prepared [29]. Such a view received support from the embryo transfer experiments of M.C. Chang in rabbits who demonstrated that the stage of embryonic development required to be synchronised with that of uterine proliferation if pregnancy was to ensue [30]. Nonetheless, there is abundant evidence that such reasoning is not tenable in primates. Classical experiments in infertile women involving transplantation of an ovary to the uterus in instances of blocked Fallopian tubes indicate that pregnancies may have been generated by this approach. If so, neither oocyte nor spermatozoon would have been exposed to the Fallopian tubes, although fluids from these structures may have entered the uterus to influence both gametes and the embryo. More persuasive still is the evidence from infertility clinics. Introduction of secondary oocytes directly into the uterine cavity in combination with insemination can generate full-term pregnancies. A substantial overlap in the composition of tubal and uterine fluids in primates may be a principal explanation for such success [31].

As an extension of these proposals concerning the absence of distinguishable fluid compartments, and in conjunction with endometrial fragments developing within the Fallopian tube, the fluid and tissue milieu so generated may offer an explanation for tubal ectopic pregnancy [32].

\section{EMBRYONIC GENE EXPRESSION}

A final topic concerns molecular considerations. The embryonic genome commences to be expressed during passage of the embryo along the Fallopian tubes, and components of the fluid milieu may have a specific impact on such expression. Diverse proteins and glycoproteins could be influencing the extent of early gene expression. There is accumulating evidence that in vitro procedures can alter gene expression in developing embryos $[33,34]$, and they are certainly implicated in perturbations such as the Large Offspring Syndrome. Accordingly, exposure of embryos to Fallopian tube fluid constituents may act to influence reproductive efficiency and normality in diverse mammalian species. Of course, such reasoning can be overlooked in relatively small numbers of in vitro experiments but definitely not in the maintenance of viable breeding populations - a biological perspective that would have been stressed by Professor Charles Thibault [35].

\section{ACKNOWLEDGEMENTS}

INRA generously sponsored the author's visit to Paris in order to participate in the Symposium. Mrs Frances Anderson kindly prepared the typescript.

\section{REFERENCES}

[1] Thibault C. Physiology and physiopathology of the Fallopian tube. Int J Fertil 1972, 17: 113.

[2] Hunter RHF, Léglise PC. Polyspermic fertilisation following tubal surgery in pigs, with particular reference to the rôle of the isthmus. J Reprod Fertil 1971, 24: 233-246.

[3] Hunter RHF, Léglise PC. Tubal surgery in the rabbit: fertilisation and polyspermy after resection of the isthmus. Am J Anat 1971, 132: 45-52.

[4] Thibault C. Analyse comparée de la fécondation et de ses anomalies chez la brebis, la vache et la lapine. Ann Biol Anim Biochim Biophys 1967, 7: 5-23. 
[5] Du Mesnil du Buisson F, Dauzier L. Distribution et résorption du sperme dans le tractus génital de la truie: survie des spermatozoides. Ann Endocrinol 1955, 16: 413-422.

[6] Hunter RHF. Pre-ovulatory arrest and periovulatory redistribution of competent spermatozoa in the isthmus of the pig oviduct. J Reprod Fertil 1984, 72: 203-211.

[7] Hunter RHF, Nichol R. Transport of spermatozoa in the sheep oviduct: pre-ovulatory sequestering of cells in the caudal isthmus. $\mathrm{J}$ Exp Zool 1983, 228: 121-128.

[8] Hunter RHF, Wilmut I. The rate of functional sperm transport into the oviducts of mated cows. Anim Reprod Sci 1982, 5: 167-173.

[9] Hunter RHF, Wilmut I. Sperm transport in the cow: peri-ovulatory redistribution of viable cells within the oviduct. Reprod Nutr Dév 1984, 24: 597-608.

[10] Hunter RHF, Nichol R, Crabtree SM. Transport of spermatozoa in the ewe: timing of the establishment of a functional population in the oviduct. Reprod Nutr Dév 1980, 20: 1869_ 1875.

[11] Fléchon JE, Hunter RHF. Distribution of spermatozoa in the utero-tubal junction and isthmus of pigs, and their relationship with the luminal epithelium after mating: a scanning electron microscope study. Tissue Cell 1981, 13: $127-139$.

[12] Hunter RHF, Fléchon B, Fléchon JE, Pre- and Peri-ovulation distribution of viable spermatozoa in the pig oviduct: a scanning electron microscope study. Tissue Cell 1987, 19: 423436.

[13] Hunter RHF, Fléchon B, Fléchon JE. Distribution, morphology and epithelial interactions of bovine spermatozoa in the oviduct before and after ovulation: a scanning electron microscope study. Tissue Cell 1991, 23: 641656.

[14] Racey PA, Suzuki F, Medway L. The relationship between stored spermatozoa and the oviducal epithelium in bats of the genus Tylonycteris. In: Hafez ESE, Thibault C (Eds), The Biology of Spermatozoa, Karger, Basel, 1975, p 123-133.

[15] Hunter RHF, Nichol R. A pre-ovulatory temperature gradient between the isthmus and ampulla of pig oviducts during the phase of sperm storage. J Reprod Fertil, 1986, 77: 599_ 606.

[16] Hunter RHF. Physiology of the Graafian Follicle and Ovulation. Cambridge University Press, Cambridge, 2003.
[17] Hunter RHF, Bøgh IB, Einer-Jensen N, Müller S, Greve T. Pre-ovulatory Graafian follicles are cooler than neighbouring stroma in pig ovaries. Human Rep 2000, 15: 273-283.

[18] Roblero L, Biggers JD, Lechene CP. Electron probe analysis of the elemental microenvironment of oviducal mouse embryos. J Reprod Fertil 1976, 46: 431-434.

[19] Nichol R, Hunter RHF, Garner DK, Leese HJ, Cooke GM. Concentrations of energy substrates in oviductal fluid and blood plasma of pigs during the peri-ovulatory period. J Reprod Fertil 1992, 96: 699-707.

[20] Hunter RHF. Modulation of gamete and embryonic microenvironments by oviduct glycoproteins. Mol Reprod Dev 1994, 39: 176-181.

[21] Yaniz JL, López-Gatius F, Santolaria P, Mullins KJ. Study of the functional anatomy of bovine oviductal mucosa. Anat Rec 2000, 260: 268-278.

[22] Ellington JE, Ignotz GG, Ball BA, MeyersWallen VN, Currie WB. De novo protein synthesis by bovine uterine tube (oviduct) epithelial cells changes during coculture with bull spermatozoa. Biol Reprod 1993, 48: 851-885.

[23] Fazeli A, Duncan AE, Watson PF, Holt WV. Sperm-oviduct interaction: induction of capacitation and preferential binding of uncapacitated spermatozoa to oviductal cells in porcine species. Biol Reprod 1999, 60: 879_ 886.

[24] Hunter RHF. The Fallopian Tubes: Their Rôle in Fertility and Infertility. Springer-Verlag, Berlin \& Heidelberg, 1988.

[25] Motta PM, Nottola SA, Familiari G. Cumulus corona cells at fertilisation and segmentation. A paracrine organ. In: Motta PM (Ed), Microscopy of Reproduction and Development: A Dynamic Approach, Antonio Delfino Editore, Rome, 1997, p 177-186.

[26] Hunter RHF, Einer-Jensen N. Potential amplification of early pregnancy signals by ovarian follicular cells in suspension within the Fallopian tube. Zygote 2003, 11: 237-243.

[27] Hunter RHF, Einer-Jensen N, Greve T. Somatic cell amplification of early pregnancy factors in the Fallopian tube. A Malpighi Symposium in Memory of Pietro Motta, Rome, Ital J Anat Embryol 2005, 110 (Suppl I): 195-203.

[28] Hunter RHF. Fallopian tube physiology: preliminaries to monospermic fertilisation and cellular events post-fertilisation. In: Ernst Schering Research Foundation Workshop 52, Chap 11, Springer, Berlin and Heidelberg, 2005, p 245-261. 
[29] Corner GW. The Hormones in Human Reproduction. Princeton University Press, Princeton, 1942.

[30] Chang MC. Development and fate of transferred rabbit ova or blastocyst in relation to the ovulation time of recipients. J Exp Zool 1950, 114: 197-225.

[31] Hunter RHF. Have the Fallopian tubes a vital role in promoting fertility? Acta Obstet Gynecol Scand 1998, 77: 475-486.

[32] Hunter RHF. Tubal ectopic pregnancy: a patho-physiological explanation involving endometriosis. Hum Reprod 2002, 17: 16881691.

[33] Wrenzycki C, Herrmann D, Carnwath JW, Niemann H. Alterations in the relative abundance of gene transcripts in preimplantation bovine embryos cultured in medium supple- mented with either serum or PVA. Mol Reprod Dev 1999, 53: 8-18.

[34] Lonergan P, Rizos D, Gutierrez-Adan A. Temporal divergence in the pattern of messenger RNA expression in bovine embryos cultured from the zygote to blastocyst. Biol Reprod 2003, 69: 1424-1431.

[35] Thibault C, Levasseur MC, Hunter RHF. Reproduction in Mammals and Man. Ellipses, Paris, 1993.

[36] Hunter RHF. Local action of progesterone leading to polyspermic fertilisation in pigs. $\mathrm{J}$ Reprod Fertil 1972, 31: 433-444.

[37] Hunter RHF, Cook B, Poyser NL. Regulation of oviduct function in pigs by local transfer of ovarian steroids and prostaglandins: a mechanism to influence sperm transport. Eur J Obstet Gynecol Reprod Biol 1983, 14: 225232 